Article

\title{
Semantic 3D Modeling Based on CityGML for Ancient Chinese-Style Architectural Roofs of Digital Heritage
}

\author{
Lin $\mathrm{Li}^{1,2,3, *}$, Lei Tang ${ }^{1}$, Haihong Zhu ${ }^{1}$, Hang Zhang ${ }^{1}$, Fan Yang ${ }^{1}$ and Wenmin Qin ${ }^{1}$ \\ 1 School of Resource and Environmental Sciences, Wuhan University, 129 Luoyu Rd., Wuhan 430079, China; \\ leitang@whu.edu.cn (L.T.); hhzhu@whu.edu.cn (H.Z.); hangzhang@whu.edu.cn (H.Z.); \\ yhlx125@163.com (F.Y.); 2015102050003@whu.edu.cn (W.Q.) \\ 2 Shenzhen Research Center of Digital City Engineering, Shenzhen 518034, China \\ 3 The Key Laboratory for Geographical Information Systems, Ministry of Education, Wuhan 430079, China \\ * Correspondence: lilin@whu.edu.cn; Tel.: +86-138-7150-4963
}

Academic Editors: Sisi Zlatanova and Wolfgang Kainz

Received: 4 March 2017; Accepted: 25 April 2017; Published: 27 April 2017

\begin{abstract}
Ancient Chinese-style architecture has received increased attention during the last century as a segment of cultural heritage and is of great significance, specifically in regard to the process of digitizing and modeling these buildings to preserve and protect this heritage. Because the roof form reflects the age of the structure, the structural character and the historical culture of the ancient building, constructing a refined model for the roof is a primary aspect of the 3D modeling procedure. To avoid cumbersome traditional modeling approaches that use geometry units, such as points, lines and triangles, a flexible semantic method is proposed in this study to improve modeling efficiency and reduce the professional requirements. In this method, a two-level semantic decomposition of the roof is presented according to the characteristics of ancient Chinese-style architecture. The structural level reveals the basic components that determine its structural shape, and the decorative level refers to the attached components that influence the exterior appearance. The assembly validity of the decomposed elements and the combined diversity of the integrated entities are ensured by topological constraints and derived transformations of the semantic components. This proposed method was implemented by utilizing CityGML (City Geography Markup Language) via the ADE (Application Domain Extension) mechanism and was tested by modeling the principal buildings included in the Palace Museum.
\end{abstract}

Keywords: ancient Chinese-style architecture; roof; semantic modeling; topology; CityGML

\section{Introduction}

Since the 20th century, heritage preservation and protection regarding forms both tangible and intangible have received growing and enthusiastic international attention [1-8]. Several important principles were promulgated concomitantly during this time period, where the most significant guideline was the International Charter for the Conservation and Restoration of Monuments and Sites, commonly referred to as the Venice Charter 1964, which set a remarkable benchmark for principles that govern architectural conservation and restoration [9]. Currently, a unique focus is placed on surrogating fragile objects, such as ancient architecture [10]. Digital modeling is one of the most effective and available measures toward achieving this goal.

Ancient Chinese architecture, as an art, is the essence of Chinese cultural heritage [11]. It has an indigenous and unique system of construction that has retained its principal characteristic from prehistoric times to the present and has spread its influence to other countries, such as Korea and 
Japan [12], as shown in Figure 1a-c. Unfortunately, a mass of the artistic architectures disappeared due to the brittle timber structures and natural or human-made disasters. 3D digital modeling technology hence has become increasingly necessary to understand and restore them. Additionally, curved roofs act as the peculiarly characteristic and ornate parts and are the most complicated and difficult to construct, although they are aesthetically important. That is also why current Chinese antique buildings (Figure 1d) are composed of a traditional roof and a modern body. To this end, this paper places the research emphasis on 3D digital modeling for ancient Chinese-style architectural roofs.

(a)

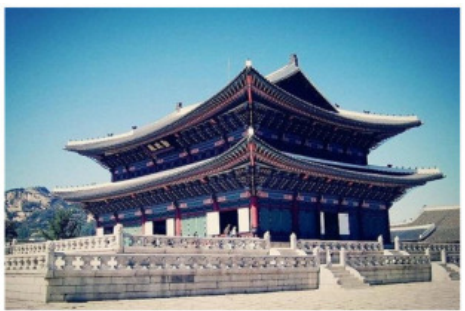

(c)

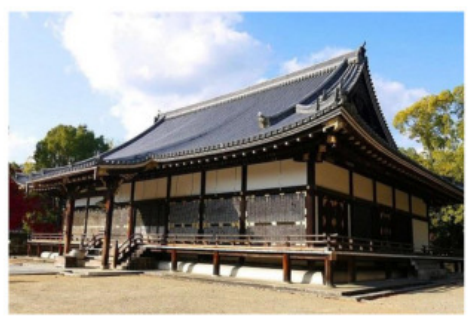

(b)

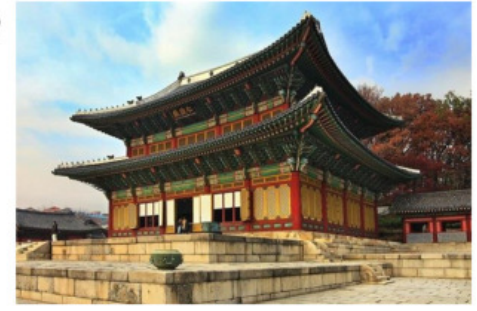

(d)

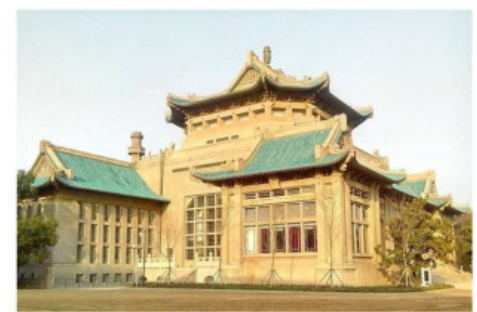

Figure 1. Ancient and antique Chinese-style architecture. (a) Qinzheng Palace in Beijing, China; (b) Renzheng Palace in Seoul, Korea; (c) Renhe Temple in Kyoto, Japan; (d) antique buildings at Wuhan University, China.

Modeling buildings has been performed by scholars adopting various processing methods that can be classified into two fundamental categories: data-driven and model-driven methods [13]. Data-driven methods utilize a LiDAR point cloud dataset for a primary data source, which utilizes several segmentation algorithms, such as region growing (RG) [14], the 3D Hough transform [15], feature clustering [16], model fitting [17] and random sample consensus (RANSAC) [18,19]. Polyhedral building models are generated from the planar segmented patches through intersection and step-edge generation and are then regulated by certain construction rules to improve the shape. Although building models, even those that incorporate complex roof shapes, can be reconstructed using the above approaches, the modeling process and corresponding object structures may be hampered and deformed when certain features lack original data [20]. To avoid this drawback, aerial imagery was introduced as supplemental data to improve the accuracy because of its high resolution. Therefore, certain studies have used both LiDAR data and aerial imagery for building reconstruction during the last decade [21-25]. Because of this improved process, building models can incorporate acceptable shape effects, although they are always geometric volumes that disregarded important semantic information about the structures.

To obtain visually-realistic and topologically-accurate building models that include semantic descriptions, a model-driven strategy was proposed. Certain scholars have applied constructive solid geometry (CSG)-based methods, which combine simple basic primitive structures (cube, cylinder, cone, sphere, etc.) and use Boolean operators (intersection, union, subtraction, etc.) for building modeling [26-29]. Thus, a complex building, or a structure that includes a complex roof, could be reconstructed by assembling basic primitive structures that were designed in a library. The models grouped by CSG primitive structures that include few control parameters possess semantic information, and their processes are relatively easy to apply. However, properly decomposing complex buildings 
into CSG primitives is open and sophisticated, and the CSG modeling process generally requires manual adjustments.

The validity of assembling primitives into the correct building style and structure is another challenge, which may be addressed by incorporating semantic constraints [30]. CityGML [31] is the standard for the representation and exchange of 3D city models and contains rich information in terms of geometry, semantics and topology. With respect to semantic topology, CityGML adopts a simple XLinkconcept to represent the interrelations between different geometric aggregates or thematic features [32]. Gröger and Plümer extended the existing axiomatic characterization of 3D surfaces to guarantee the semantic topological consistency of semantic objects, such as bridges and tunnels, in 3D city models [33]. A semantics-constrained profiling approach was proposed that ensured the consistency of the geometrical, topological and semantic relationships when profiling complex 3D city models [34]. Nevertheless, topological relationships between the semantic features were not improved or detailed when these approaches were used. To develop a more comprehensive topology in CityGML, a two-level topological model (semantic level and geometric level) is proposed to represent 3D topological relationships [35].

In alignment with the above-mentioned studies and considering that the structure of ancient Chinese-style architectural roofs is fairly complicated and includes a variety of detailed components, including a uniquely-distinguished Chinese-style and time-honored cultural spirit, an improved flexible semantic 3D model approach is proposed to adapt to our research theme more accurately. The contributions of this study are as follows: (1) a two-level semantic decomposition of roofs in terms of structure and decoration is proposed according to the characteristics of ancient Chinese-style architecture; (2) the corresponding topological constraints and derived transformations are determined; (3) an extension model, ACRoofADE, based on CityGML, is developed using the Application Domain Extension (ADE) mechanism; and (4) several LODs (levels of detail) are precisely described for a roof structural model.

\section{Ancient Chinese-Style Architecture and Roofs}

Ancient timber architecture is an important component of Chinese civilization and has profoundly influenced certain East Asian countries. For this reason, in our study, we refer to these structures as ancient Chinese-style architecture, where many such structures are designated as historical heritage sites, such as the Fogong Temple in Shanxi, China (built in 1056); Nam Dae Mun in Seoul, South Korea (rebuilt in 1448); and the Horioji Temple in Nala, Japan (built in 682) [12]. As one of the world's three mainstream and historic building systems, Chinese-style architecture has unique characteristics, relative to European and Islamic architectural styles.

\subsection{Characteristics of Ancient Chinese-Style Architecture}

Architecture refers to the art of creating a 3D artificial form to fulfill certain functions. The factors that affect architectural forms in a local context include culture, building materials and constructional methods. When one of these factors changes, the building forms and styles are altered accordingly to respond to the emerging situation. In Chinese architectural history, forms and styles maintained consistent characteristics and have not been dramatically altered by the above-mentioned factors; Chinese culture has remained relatively homogeneous from prehistoric times to the present [36].

\subsubsection{Timber Structures}

The majority of Chinese ancient buildings use timber rather than masonry for the frame of their primary system. Timber pillars, beams, purlins and rafters form the frame, while walls and windows separate rooms without bearing the weight of the entire structure. Each building is composed of likely thousands of timber pieces, based on logic and geometric organization, which bite each other by tenon-and-mortise under a certain acceptable error [37]. Wood was the primary architectural material used for Chinese ancient construction and was selected based on natural and geographical conditions. 
Additionally, Chinese ancestors believed that life was connected with nature and that eternal emotions could be obtained by coexisting with the universe. Therefore, wood was adopted rather than stone, which is animate, and architecture was perceived as a life body that humans could extend with natural alternation [38].

\subsubsection{Curved and Large Roofs Styles}

Relative to modern buildings that put greater emphasis on decorating exterior walls, ancient Chinese architecture is an exception in that it focuses more attention on the roof design [39]. The study of Chinese buildings is primarily a study of anatomy that incorporates section drawing and indicates that the roof supports in Chinese timber-frame construction differ fundamentally from conventional Western triangular roof trusses that dictate the rigidity of straight pitched roofs. In regard to the timber structure, Chinese roof shapes were markedly flexible and were curved or concave to protect against moisture migration (i.e., rain or melting snow seeping back into the roof) [40]. Moreover, the roof volume was a significant proportion of the entire building [41], and large roofs resulted in a profound and stunning impression because of their gorgeous, aesthetic and exquisite appearance. The design approach is a primary research topic of this study and is detailed in the following sections.

\subsubsection{Standard Entity and Aggregate Group}

Ancient Chinese buildings, including palace halls, commoner houses, temples, pagodas, pavilions, ceremonial gates and fences, were an aggregate group in the past that consisted of a series of standard building entities. For certain religious and institutional reasons, ancient Chinese-style buildings generally followed uniformly-prescribed rules and regulations, such as the vertical sandwich fiber structure (roof, wall and base) and horizontal symmetry characteristics, which were recorded in two important theoretical books: YingZaoFaShi(Building Standards) during the Song Dynasty and GongChengZuoFa(Structural Regulations) during the Qing Dynasty. With respect to a monotonous single entity, the building clusters incorporate abundant and varying layouts and embody their hierarchical intention. Therefore, we should analyze the overall cluster to comprehend the full impression of ancient Chinese architecture.

\subsubsection{Variety of Colors and Decorations}

If Western architecture refers to the building of sculptures, then the ancient Chinese style refers to building with color. This phenomenon is illustrated in the use of two different construction materials. Colored drawing was adopted not only for aesthetic perceptions, but also to protect perishable and hygroscopic wood structures. Additionally, the colors used in ancient Chinese architecture had been endowed with a sacred mission associated with the feudal hierarchy (e.g., yellow could only be used by royal families). The decorations assumed similar roles that further developed and deepened the spatial morphology and artistic expression of the ancient buildings. It was not until recently that the colors and decorations that were used in antique buildings lost their actual functional effects because of the development of new construction materials and technologies. However, the significance attached to colors and decorations persists to a certain extent.

\subsection{Roofs in Ancient Chinese-Style Architecture}

Since ancient times, China has been famous for being a state of ceremonies. A ceremony refers to a social institution that influences every aspect of life, including architecture. Confucianism significantly influenced ancient Chinese architecture; its strict hierarchy was manifested through architectural volume, scale, roof style, decoration and color. The most eye-catching component of ancient architecture, the roof, performed the important function of the facade and included all of the characteristics mentioned above. Meanwhile, the roof included the most distinct ritual feature, as illustrated by the following representative types of roofs (Figure 2). 
A hip roof (in this study, we adopted the translational terms related to ancient Chinese-style architecture used in "A pictorial history of Chinese architecture" written by S.C.Liang) consists of five ridges and four slopes and was the most advanced form applied to palace halls and Confucius temples in feudal society. A flush gable roof consists of five ridges and two slopes and was the most common form that was used by ordinary commoners. An overhanging gable roof is similar to a flush gable roof, but it extends both side eaves in the horizontal direction to provide shelter from rain. A gable-hip roof has nine ridges, two full slopes and two half slopes. This style of roof appears similar to a flush gable roof or overhanging gable roof superimposed onto a hip roof and is ranked second only to the hip roof because of its owner's official position. There is another type of pavilion roof that includes pyramidal and round styles that could often be seen in small pavilions that did not have bounding walls. Furthermore, round ridges and multiple eaves were typical transformations based on the above-mentioned roof types.

(a)

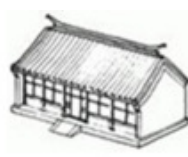

(e)

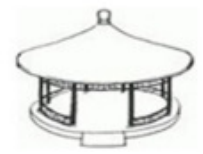

(b)

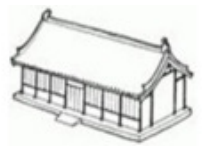

(f)

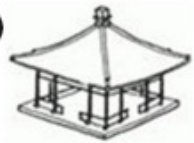

(c)

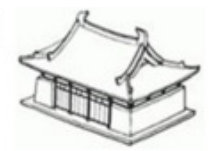

(g)

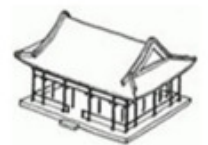

(d)

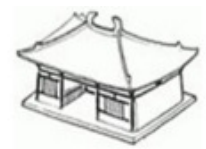

(h)

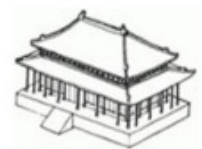

Figure 2. Examples of common ancient Chinese-style architecture that incorporated different roof styles. (a) Hip roof; (b) flush gable roof; (c) overhanging gable roof; (d) gable-hip roof; (e) pyramidal pavilion roof; (f) round pavilion roof; (g) round gable-hip roof; (h) double-eave hip roof.

\section{Two-Level Semantic Decomposition of the Roofs}

Through the above descriptions regarding roof characteristics, a conclusion could be drawn that architecture uses similar styles in the details that can be disassembled into a series of components. In this study, we analyzed ancient roof styles using the same principle; then, several roof semantic components were extracted and abstracted to analyze how the roofs were constructed. Two primary categories are used to classify roof components: structural and decorative.

\subsection{Structural Semantic Components}

Structural semantic components include the primary ridge, the vertical ridge, the angle ridge, the slope surface, the primary eave, the overhanging eave and the gable wall, as illustrated in Figure 3 . The eight representative roof styles illustrated in Table 1 could be structured by these components based on certain regular patterns.

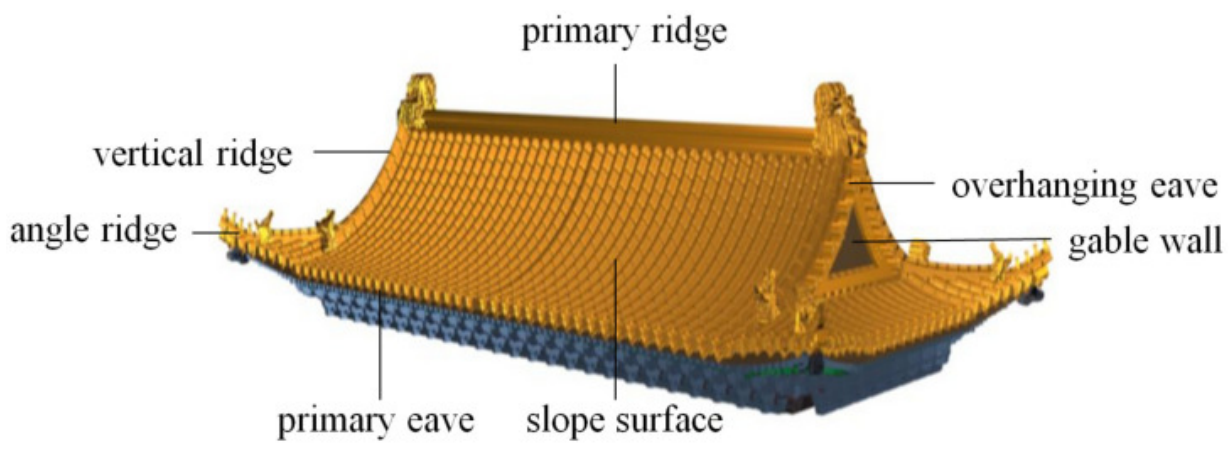

Figure 3. Structural semantic components. 
Table 1. Eight representative roof types and their semantic structures.

\begin{tabular}{|c|c|c|c|c|c|c|c|c|}
\hline \multirow{2}{*}{ Roof Type } & \multirow{2}{*}{ Roof Shape } & \multicolumn{7}{|c|}{ Semantic Structural Components ${ }^{1}$} \\
\hline & & Primary Ridge & Vertical Ridge & Angle Ridge & Primary Eave & Overhanging Eave & Slope Surface & Gable Wall \\
\hline Flush gable & & 1 & 4 & - & 2 & - & 2 & 2 \\
\hline Round flush gable & & - & 4 & - & 2 & - & 2 & 2 \\
\hline Overhanging gable & & 1 & 4 & - & 2 & 4 & 2 & 2 \\
\hline Flush gable-hip & & 1 & 4 & 4 & 4 & - & 4 & 2 \\
\hline Overhanging gable-hip & & 1 & 4 & 4 & 4 & 4 & 4 & 2 \\
\hline Hip & & 1 & 4 & - & 4 & - & 4 & - \\
\hline Pyramidal pavilion & & - & $*(\geqslant 3)$ & - & $*(\geqslant 3)$ & - & $*(\geqslant 3)$ & - \\
\hline Round pavilion & & - & - & - & 1 & - & 1 & - \\
\hline
\end{tabular}

${ }^{1}$ The numbers in the table represent the number of semantic structural components; “-" implies that the component does not exist; and "* $(\geqslant)$ " implies that the component can be duplicated more than three times. 


\subsubsection{Ridge}

The primary ridge lies on the top of the roof and covers the junctions of slope surfaces. This ridge is always straight from the left to the right end, but it has two tails that are cocked upward and are occasionally constructed with earthenware. This ridge was replaced by a round ridge when it exited into certain garden buildings to include a beauty of feminine tenderness. Occasionally, this ridge was replaced by a pagoda top when it was used for a pavilion roof. A vertical ridge was placed at the primary ridge ends or on a pagoda top at the under eave. An angle ridge is a specific ridge that is only used with a gable-hip roof and connects to the end of the vertical ridge. A horizontal ridge is used in multi-eave (multiple eaves) buildings.

\subsubsection{Eave}

The primary eave refers to the marginal part of the slope surface and always extends a certain distance beyond the wall to draw away heavy rains and block the Sun. This same function is realized by the overhanging eave that protects the gable wall. Multiple eaves were adopted in multi-story buildings, such as pagodas and towers, and increased the tremendous momentum.

\subsubsection{Gable Wall}

The gable wall refers to the triangular wall formed by the lateral wall and the gable roof, and it is always below the roof surface. However, the gable wall was above the roof surface in a southeast China vernacular house and was referred to as the horse-head wall because of its structural shape, which protected from fire, wind and rain. When a gable wall exists in an overhanging and hip roof, it may be hollowed-out to allow for fresh air and sufficient sunshine.

\subsubsection{Slope Surface}

The roof surfaces of traditional Chinese architecture were generally sloping and concave because of the structural grammar termed chü-chêh (raise and depress) or chü-chia (raise the truss) according to the two above-mentioned instructional books. The roof structures incorporated multiple inner cambers that were joined by several adjacent sarking boards and then covered by other coverings, such as tiles, to appear as a continuous curved surface. This resulted in a more beautiful structural appearance and provided a practical drainage function.

\subsection{Decorative Semantic Components}

The structural components included the basic structure of the roof, but the roof was embellished with decorative components, such as ch'ih-wei, ch'ui-shou, tsiang-shou, tsun-shou, pediment, wing corner, pagoda top, tiling and colored drawing.

\subsubsection{Animal Sculpture}

Ancient Chinese-style roofs were constructed using various wood blocks that connected to each other. The connection points were strengthened with iron nails or tenon joints. To avoid corrosion and efflorescence by the external natural environment, a series of symbolic animal sculptures were added to protect the roofs. Each sculpture was of a specific type in alignment with its position on the roof. Ch'ih-wei (Figure 4a) kept its shape as a Chinese dragon that connected to the end of the primary ridge after the Song Dynasty. Ch'ui-shou, tsiang-shou and tsun-shou (Figure $4 \mathrm{~b}$ ) were developed into a unified standard practice during the Ming and Qing dynasties.

\subsubsection{Pediment}

In overhanging gable roofs, pediment decorations (Figure 4c-e) were an essential component of both functional and aesthetic aspects. Several widgets were included in the pediment decorations, such as hanging fish and gable eave boards. In regard to flush gable roofs, these widgets were 
not necessary because the full gable wall effectively protected the inside purlins. However, ancient craftsmen included a similar treatment for beautification. Moreover, an enclosed pediment is another architectural solution.

\subsubsection{Wing Corner}

It is notable that the corners of ancient Chinese-style roofs are cocked and extend the graceful curves of sloped surfaces. The corner is defined as a wing corner (Figure 4f); as its name implies, this corner appears similar to a bird's wing and is supported by flying rafters.

\subsubsection{Pagoda Top}

The pagoda top (Figure $4 \mathrm{~g}, \mathrm{~h}$ ) is a particular component in pyramidal pavilion roof styles and wraps the intersection of several vertical ridges. Because of its visually-prominent position, the pagoda top emphasizes its decorative design; its shape ranges from a simple sphere to a complicated pagoda style. This same principle can be applied to a round pavilion roof.

\subsubsection{Tiling}

For all roof styles, the tiling attached to the slope surface occupies most of the area and has been regarded as the most important waterproof component of a roof. From a material perspective, the tiling falls under two primary categories [42]: gray-green tile (Figure 4i) and glazed tile (Figure 4j). Gray-green tile was used for commoners' houses, and glazed tile was used for aristocratic buildings.

\subsubsection{Colored Drawing}

Colored drawing (Figure 4k) was an important characteristic of ancient Chinese architecture, as mentioned above. The drawing patterns were exquisite rather than a simple mixture of color. A Chinese dragon or phoenix was generally used in the primary shrine of larger buildings, and mountains or flower patterns were generally used in gardens.

(a)

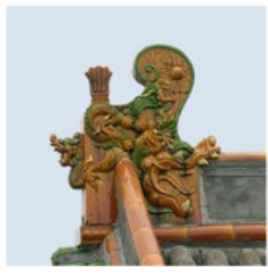

(d)

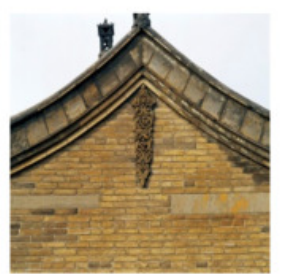

(h)

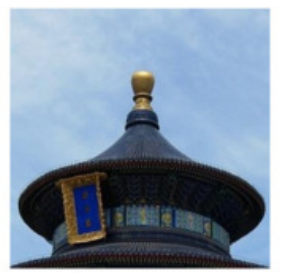

(b)

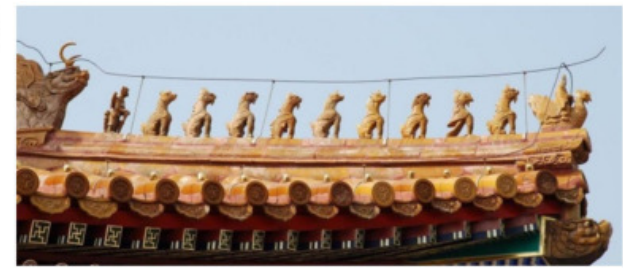

(e)

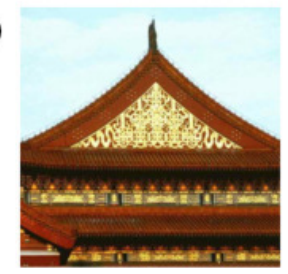

(i)

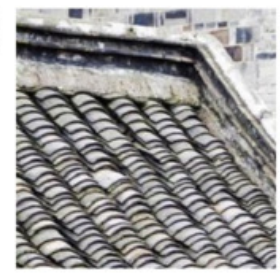

(f)

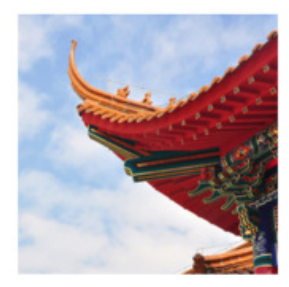

(j)

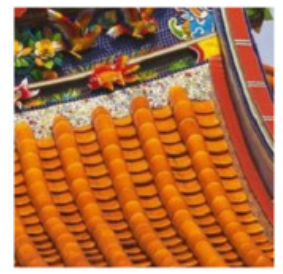

(c)

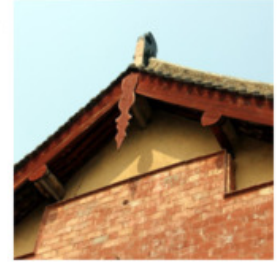

(g)

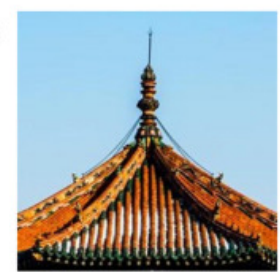

(k)

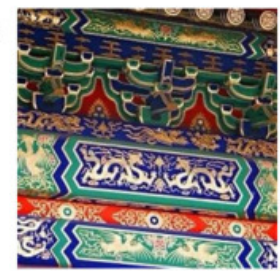

Figure 4. Decorative semantic components. (a) Ch'ih-wei; (b) Tsun-shou; (c) hanging fish on an overhanging gable roof; (d) hanging fish on a flush gable roof; (e) enclosed pediment; (f) wing corner; (g) pagoda top of pyramidal pavilion roof; (h) pagoda top of round pavilion roof; (i) gray-green tile; (j) glazed tile; (k) colored drawing. 


\section{Topology and Transformation of the Semantic Components}

Representing the semantic components of ancient Chinese-style architectural roof is only the first step in semantic modeling. The subsequent important step is how to assemble them, and here, we focus on the spatial relationships, which include topological constraints and the derived transformations. In some sense, we could form an analogy of the semantic modeling system as a language system [43]. The semantic components are the basic vocabularies, while the semantic constraint on the topology is the language grammar, which transforms the vocabularies into sentences. The transformation is then the paragraphs generated by some sentences, possibly single or multiple sentences. Without the last two relationships, the semantic components would be assembled randomly and could not present the ancient roofs in the right style and structure.

\subsection{Topological Constraints on the Semantic Components}

Topological constraints primarily include a combination of structural and decorative semantic components that were introduced in Section 3 in new models and can validate existing rough models. Spatial rules are summarized in Table 2.

Table 2. Topological constraints on the semantic components.

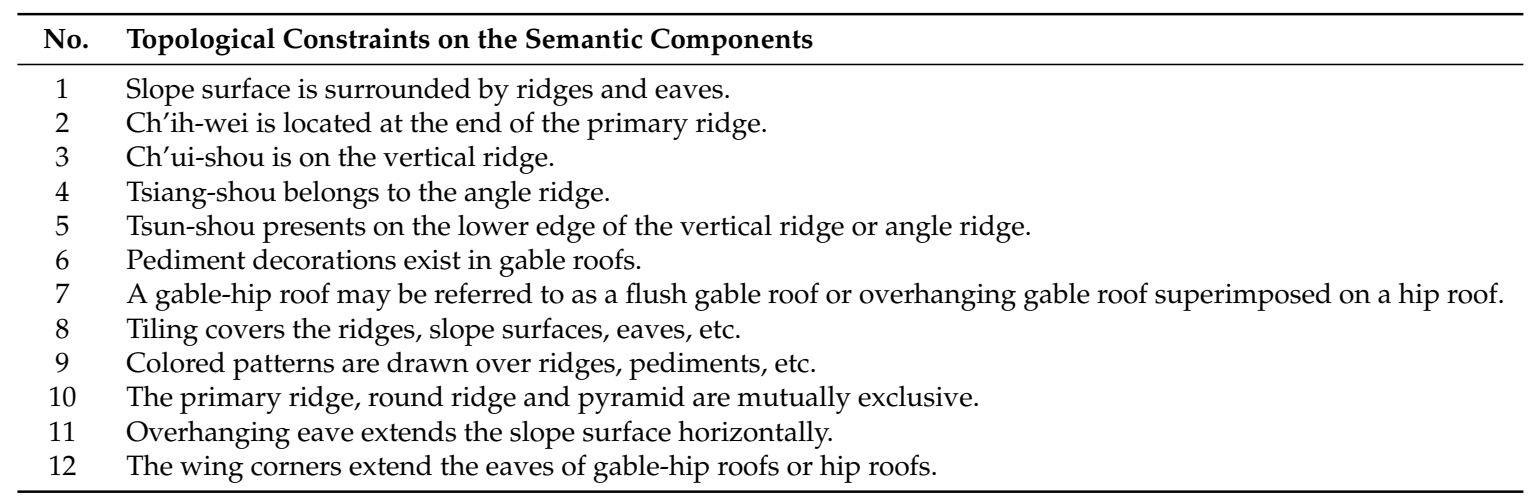

According to the descriptions in the table, we draw an additional conclusion regarding six recapitulative rules that include the following: on, cover, exist, join, extend and exclude (Figure 5). These constraints are defined relatively, with the purpose of providing an instructional direction to classify rules that would be found in future researches.

(a)

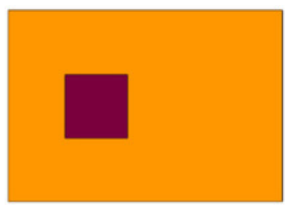

(d)

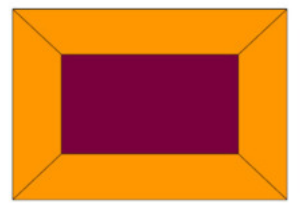

(b)

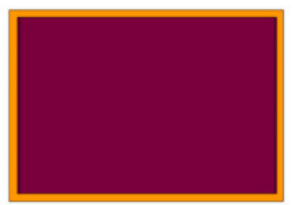

(e)

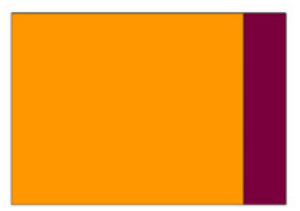

(c)

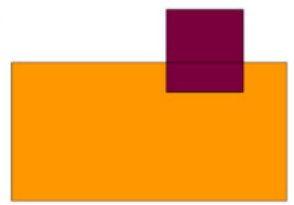

(f)

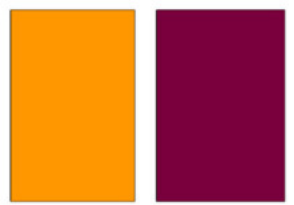

Figure 5. Six recapitulative topological constraints of semantic components. (a) On; (b) cover; (c) exist; (d) join; (e) extend; (f) exclude.

- On: This refers to a decorative component that lies on another structural component in the vertical direction. These two components are directly connected, and the joints may be perceived as an abstract point, such as Constraints 2, 3, 4 and 5 . 
- Cover: This denotes the two components that fit very closely with a wide range of contact, e.g., tiles that cover the slope surface and color patterns that cover the ridge.

- Exist: This does not have a clear positional relationship between the components, but acts as an indispensable or ornamental role, such as Constraint 6 .

- Join: This expresses a combination or the generation of the structural components. Constraints 1 and 7 are typical examples of this relationship.

- Extend: This represents the spatial extension in structural or decorative aspects that can be found in Constraints 11 and 12.

- Exclude: The exclusion between the components is a logical relationship, but represents uniqueness in a structural aspect, as demonstrated by Constraint 10.

\subsection{Derived Transformations of the Semantic Components}

Despite the above-mentioned representative roof types, there are certain derived forms that are generated for different social and environmental requirements and concurrently enrich their variety. A single-slope roof (Figure 6a) and lu-roof (Figure 6b) could be perceived as split sections of the primary roof. A single-slope roof, or half of a gable roof, as its name implies, generally acts as an assistant building and attaches to a fence or profile of another primary building. The single slope conducts more sunlight and rainwater in the rural areas of northern China. A lu-roof may be perceived as the lower half of a hip or pavilion roof, and the top profile is flat or hollow, surrounded by several primary ridges. This structure is often used in well pavilions and even jewelry boxes. There are various other types of roofs, including the dome roof, helmet roof (Figure 6c), vault roof, flat roof, cross roof, joined roof and swastika roof, being derived from the conversion of a roof surface or ridge and possibly being split, overlapped, combined, contorted or smooth.

In prior sections of this study, we described various integral forms and detailed decorations of ancient Chinese architecture. Next, we will investigate the greater building group, including characteristics and regular patterns. Three primary groups will be reviewed as follows.

\subsubsection{Multiple Roofs with Multiple Buildings}

We previously mentioned that an aggregate group is one of the most important characteristics of ancient Chinese-style architecture. The aggregate group can be retrospectively attributed to the Han dynasty that ruled more than two thousand years ago. The quadrangle courtyard, a residence that was surrounded by a four-sided building, was the primary form for Chinese dwelling houses, palaces, mausoleums and temples. Accompanied by the building group, the roof group represents the abundant diversity that reflects the skyline (Figure 6d) and symbolizes a city's or country's wealth.

\subsubsection{Multiple Roofs with Multi-Story Buildings}

In the past, a single ancient building entity was standard and ordinary; the multiple roof eaves (Figure 6e) were designed to increase the weight, size, altitude and hierarchy and enhance the majesty and solemnity. Therefore, this style of building existed principally for ancient high-ranking buildings with hip roofs or gable-hip roofs. Furthermore, certain gallery bridges and decorated archways (Figure 6f) in ancient China used similar structures.

\subsubsection{Multiple Roofs with a Single Building}

When the volume of a building roof is extremely large, it becomes necessary to seriously consider the roof image. Numerous effective treatments are available to reduce weight and clumsiness, such as dividing a large roof into several parts with a minimal dispersion in the vertical direction (Figure $6 \mathrm{~g}$ ) or redesigning the roof into smaller gable-hip roofs that cross each other while simultaneously improving the roof's ornamental value (Figure $6 \mathrm{~h}$ ). 
(a)

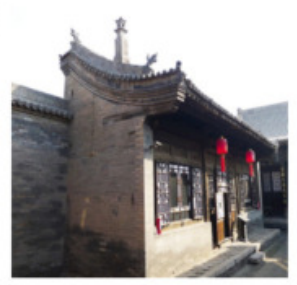

(e)

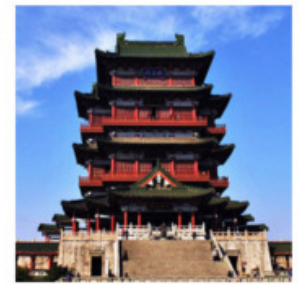

(b)

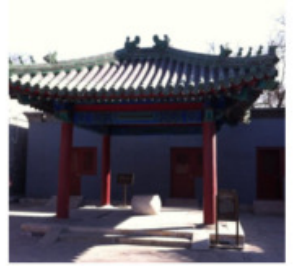

(f)

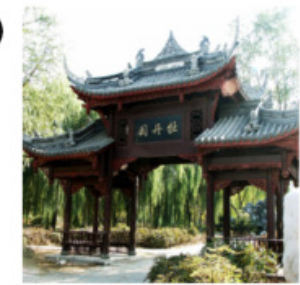

(c)

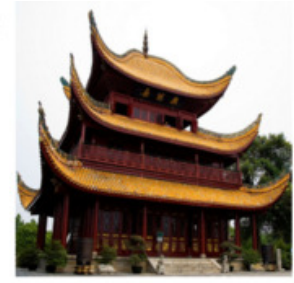

(g)

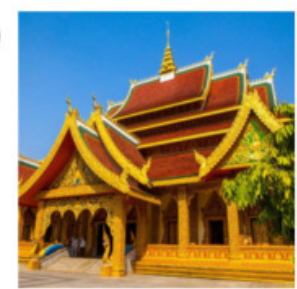

(d)

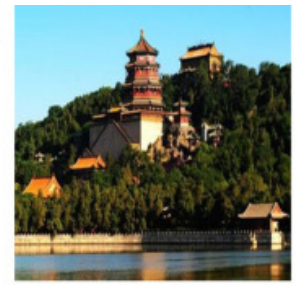

(h)

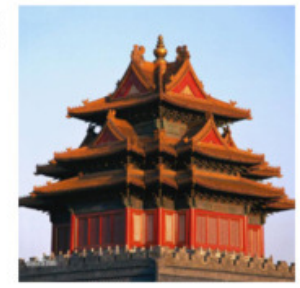

Figure 6. Derived transformation of semantic components. (a) Single-slope roof; (b) lu-roof; (c) helmet roof; (d) skyline of the Summer Palace with multiple buildings; (e) multiple roofs with a multi-story building; (f) decorated archway; (g) multiple roofs with a single building; (h) cross roofs with a single building.

\section{Semantic Modeling Based on CityGML}

We have reviewed the semantic component extraction and corresponding constraints of ancient Chinese-style architectural roofs in theory. Next, we will investigate how to realize the semantic modeling in practice. An extension of CityGML was adopted in this study because of its strong capabilities of semantic expression along with its consistent geometrical description. The supported LOD (level of detail) technique is another reason for this choice.

\subsection{An ADE for an Ancient Chinese-Style Roof}

CityGML is an open data model with an XML-based format for the storage and exchange of virtual 3D city models [44]. CityGML consists of a core module and thematic extension modules. The core module includes the basic concepts and components of the CityGML data model, and the extension modules include specific thematic fields of the virtual 3D city model, such as building. In addition, the ADEs can specify additions to the CityGML data model to adapt to the requirements of specific application domains [45]. Different research communities have developed ADEs for their requirements, with the following being examples: Noise ADE for noise mapping, HydroADE for hydrographical applications and Standard Opening ADE and URNADE for indoor navigation and mobile robotics tasks [46].

This study used the same method to incorporate the previous Building model and define a new extension module that inherits from the feature RoofSurface, called ACRoofADE, as shown in Figure 7, the abbreviation for the ADE of ancient Chinese-style architectural roofs. Although the class _AbstractBuilding in the building model includes the property roofType along with a series of enumerated values, it cannot be applied directly to our research theme because it lacks a further semantic differential. As the UML diagram illustrates, ACRoofADE expresses the semantic components with new noun class objects and represents semantic relationships with different uni-directional arrowheads. In general, the context an element takes within the association is indicated by its role, which is displayed near the target of the association. In addition, the number of elements that probably exist is also presented in the same way, as in the number in Table 1. Additional elements are distinguished from standard CityGML elements using the namespace prefix acroof, which refers to the ancient Chinese-style roof. 


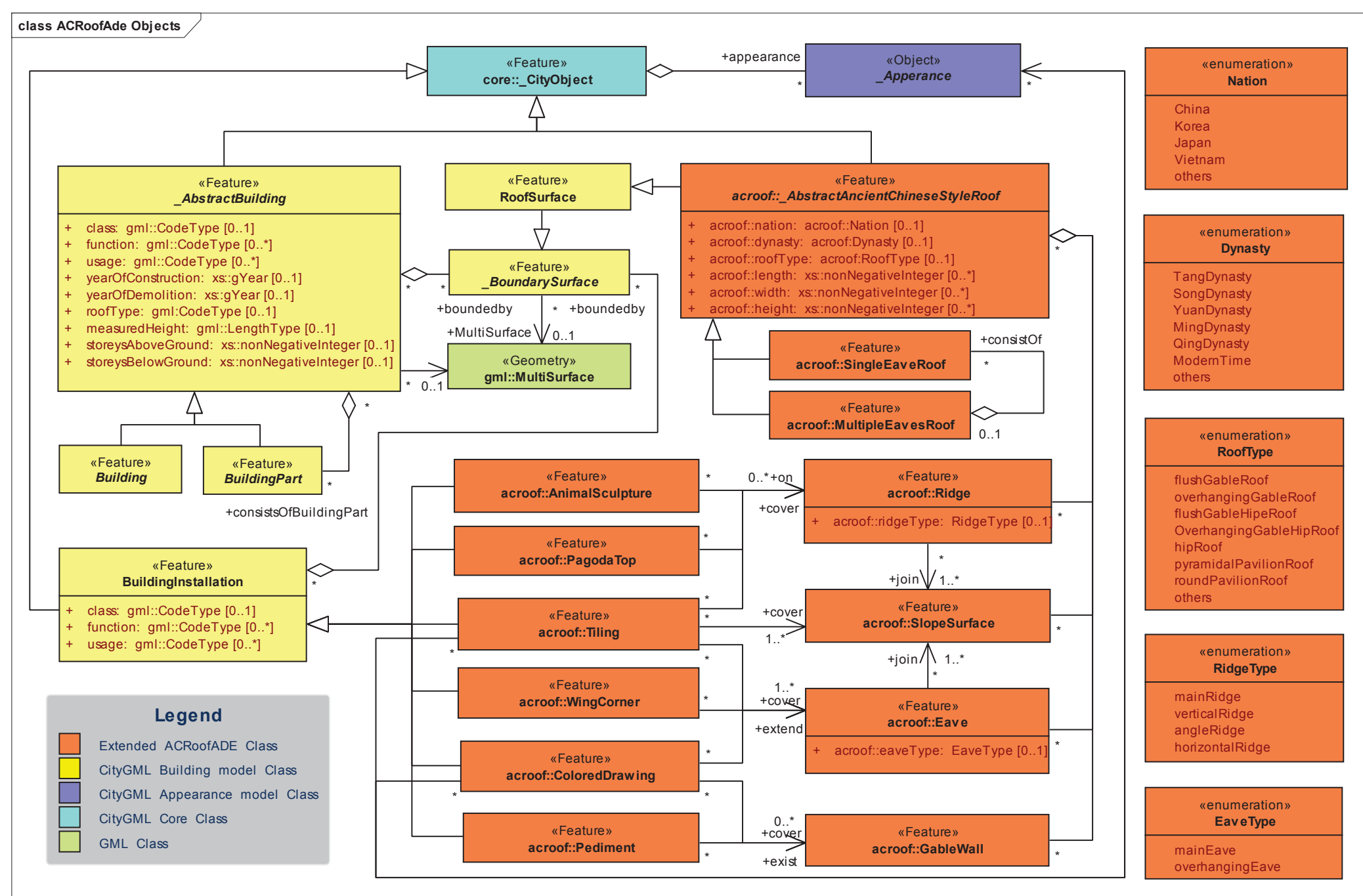

Figure 7. ACRoofADE-CityGML application domain extension for ancient Chinese-style architectural roofs (for the different colors in the figure, readers are referred to the electronic version of this paper). 


\subsection{LODs for Ancient Chinese-Style Roofs}

When modeling ancient Chinese-style roofs, there is a trade-off between better display efficiency and lower resource consumption. LODs in CityGML can address this problem to a certain extent and may reflect independent data collection processes with differing application requirements. In the building domain, LOD0 is represented by footprint or roof edge polygons; LOD1 refers to the well-known block model, which includes prismatic buildings with flat roof structures; different roof shapes with thematic boundary surfaces are expressed in LOD2; while LOD3 denotes architectural models with detailed roof structures, potentially including outer installations. LOD4 extends the LOD3 model by adding interior elements.

According to the LOD theory and the previous semantic extraction, we adjusted three detail levels (LOD1, LOD2 and LOD3) of ancient Chinese-style roof models, as seen in Table 3. LOD1 of the roof includes the simple prismatic block, and LOD2 includes structural components with monotonous colors reflecting the basic roof structure image. LOD3 is the most complicated level in our model and is equipped with various decorative widgets and surface textures to generate realistic effects. In addition, it should be noted that to reduce the complexity and storage requirements, we adopted the image mapping approach to replace the production of elaborate details for certain components.

Table 3. Ancient Chinese-style architectural roof models in LOD1, LOD2 and LOD3.

View LOD1

\subsection{The Flow of Generating a Roof Model Based on ACRoofADE}

The starting point of this study was to analyze the exterior shape of ancient Chinese-style roofs. We only needed to extract the semantic components (both structural and decorative) that influence the roof appearance from particularly abundant ancient architectural information. The UML modeling software Enterprise Architect was used to organize the modeling process for the filterable semantic elements based on CityGML and then export a well-defined schema file (.xsd). Because of the loss of ancient architectural drawing data for many different reasons, modern surveying and mapping technologies were needed for data acquisition. The formula reckoning method is another technology-assisted alternative based on the regulations and standards of ancient architectural law. The Google SketchUp software can produce a geometry model and generate a 3D model file (.obj) that can be programmatically transformed into a GML file (.gml) that is compliant with the schema definition. After following these steps, the flowchart of ACRoofADE (Figure 8), an extension of 
CityGML, is almost finished. During the entire modeling process, certain manual adjustments were necessary.

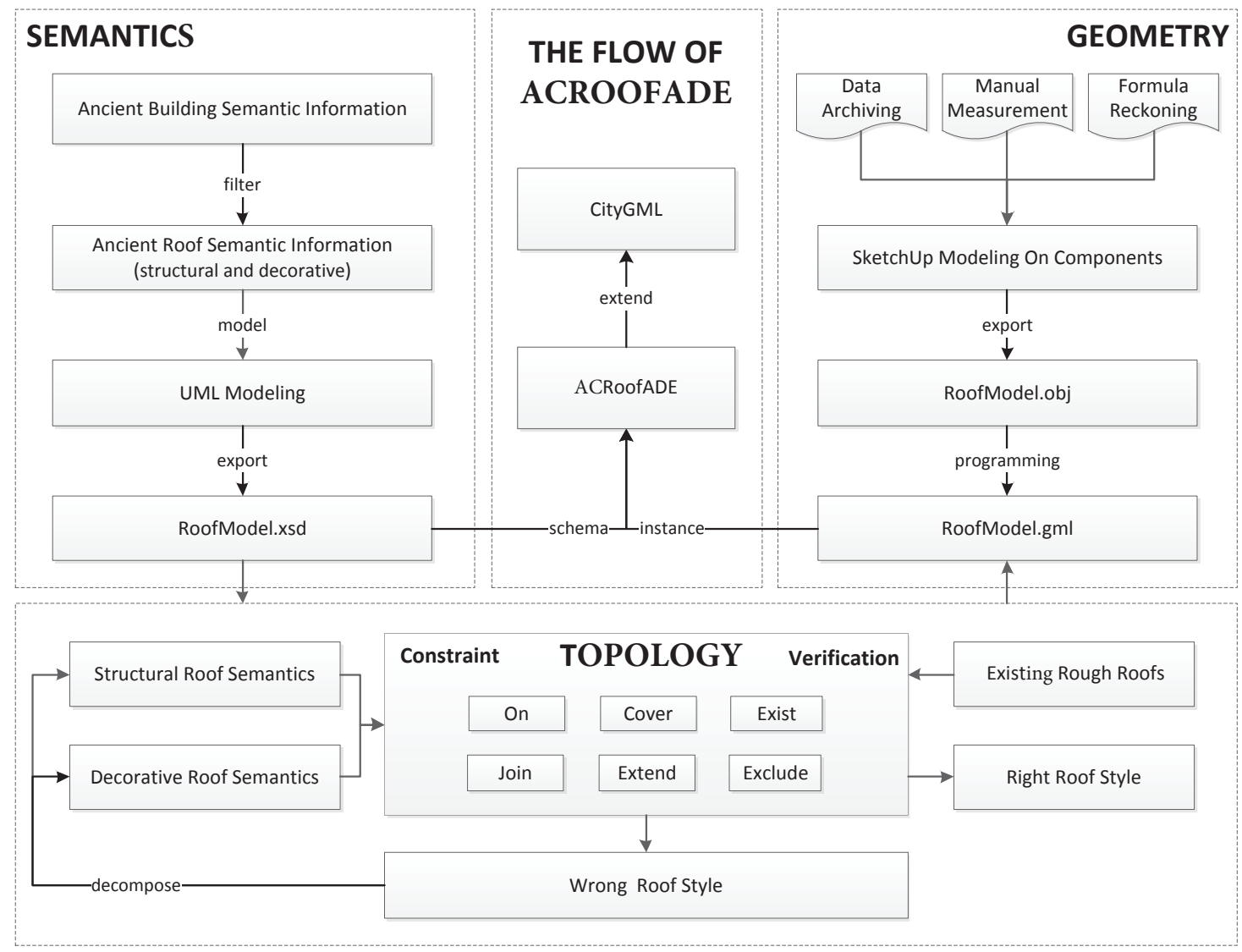

Figure 8. The flowchart of generating ACRoofADE (semantics, geometry and topology).

\section{Experimental Results}

The Beijing courtyard has a time-honored history in China and was probably first found at the courtyard site of West Zhou Dynasty (1046 BC-771 BC). During the Ming (1368-1644) and Qing (1636-1912) dynasties, distinctive four-sided courtyards were built in many regions throughout the country [47]. Here, we present the experimental results for modeling the principal buildings of the Palace Museum, which is the largest and most complete ancient architectural group currently in China [48] and includes a variety of roof styles.

The model data used for the CityGML software, named FZK Viewer, with the GML file are illustrated in the following figures. The left side of the viewer includes the hierarchical tree of ancient architectural semantic components, and the right view displays the 3D model related to the selected items on the left. Figure 9a presents an overview of the models, which include thirteen surrounding buildings and one common base ground. The Tai-He Palace model without slope surfaces is illustrated in Figure $9 \mathrm{~b}$ by filtering the components on the left to reveal the more detailed structure of the multi-eave hip roof.

To more clearly demonstrate the model process, the bottom-up generation states are presented in Figure 10, from which we can simultaneously note the components mentioned in Section 3 in a correctly-assembled ruler. Figure 11a-e illustrates the separate models in LOD2 of five palaces, therein representing a multi-eave hip, a rectangular pyramidal pavilion, a multi-eave flush gable-hip, a single-eave flush and a gable-hip roof. The corresponding LOD3 models are illustrated in Figure 11f-j. 
(a)

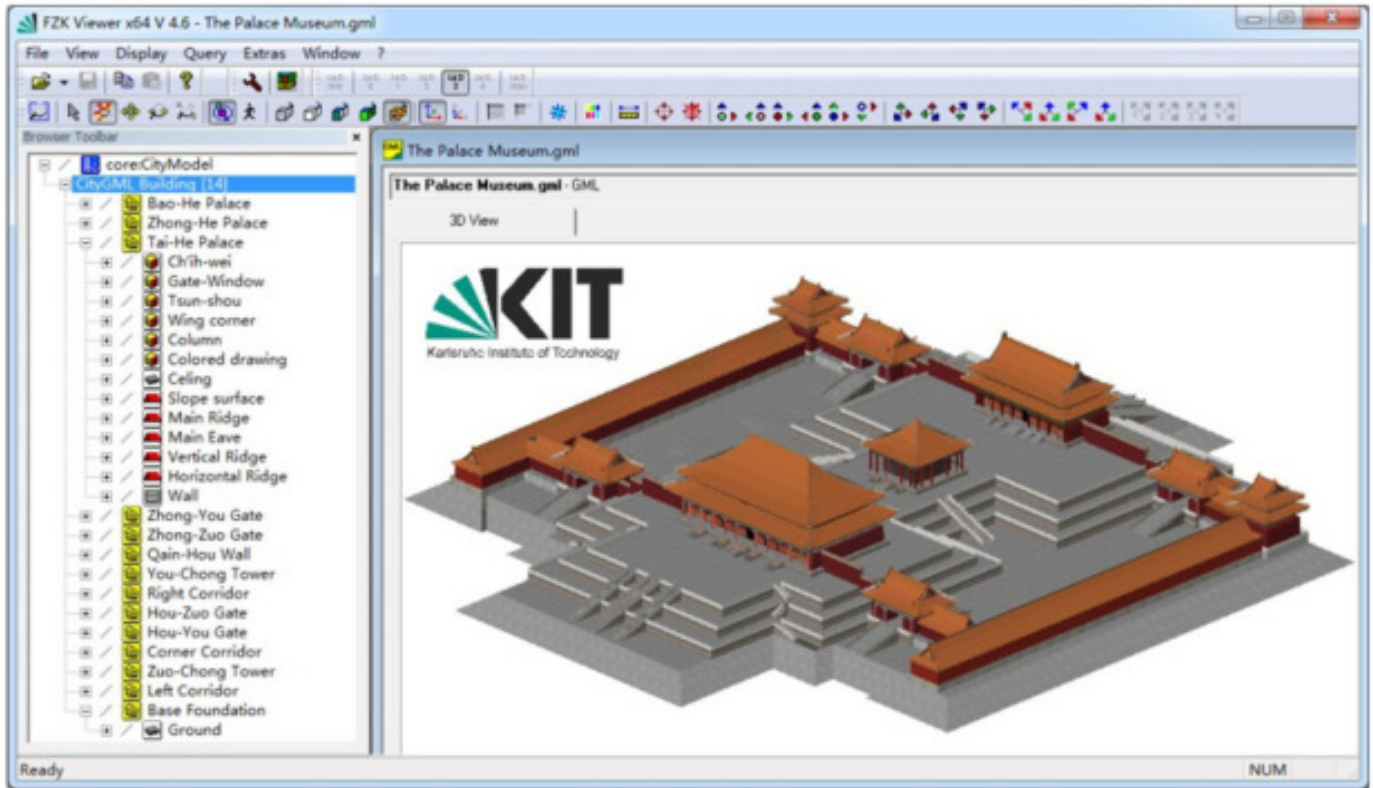

(b)

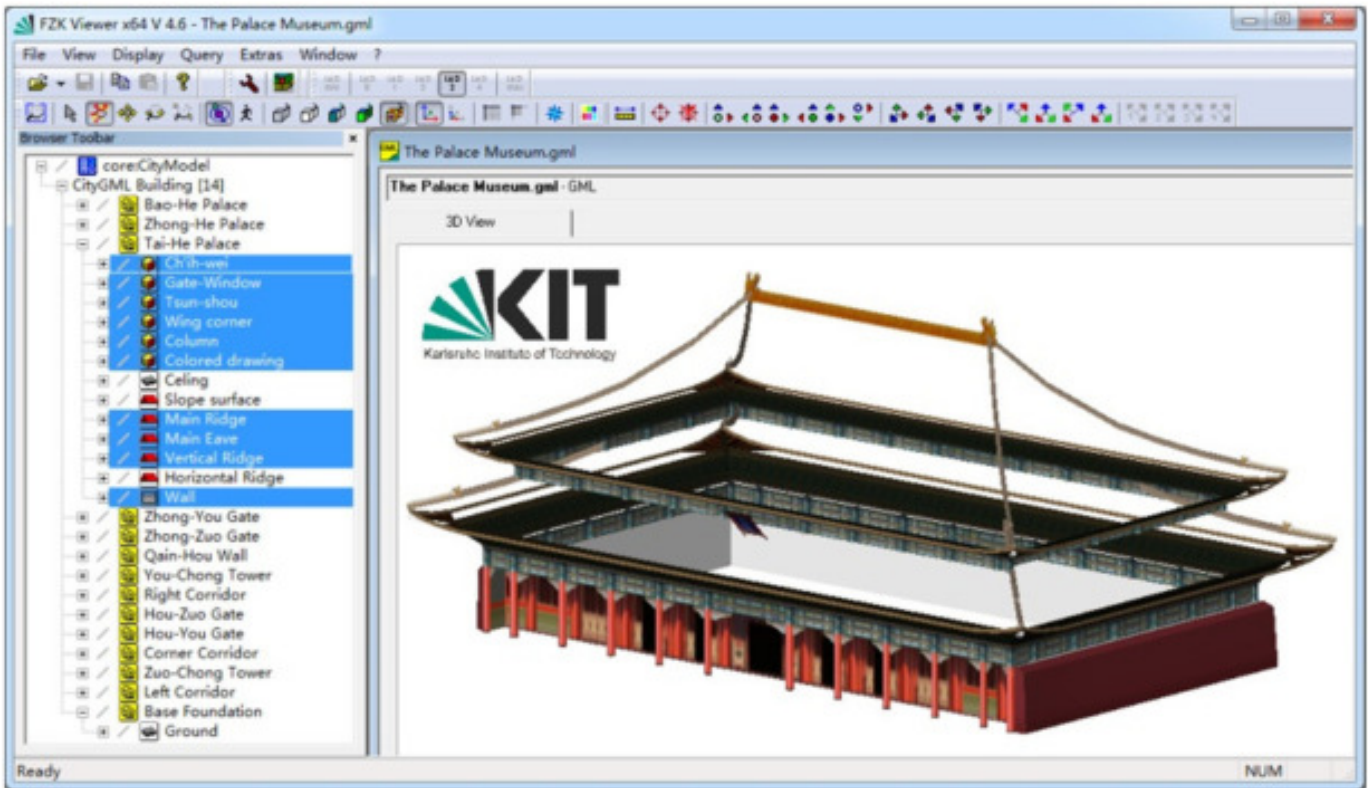

Figure 9. Experimental results. (a) An overview of the principal buildings of the Palace Museum; (b) the Tai-He Palace model without slope surfaces.

(a)

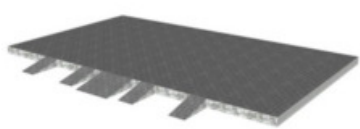

(b)

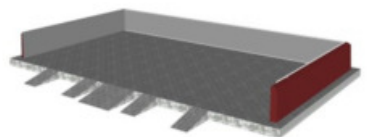

Figure 10. Cont. (c)

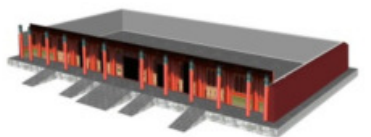


(d)

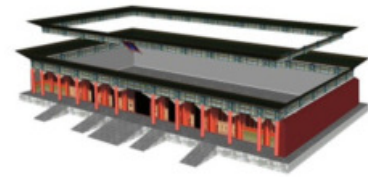

(g)

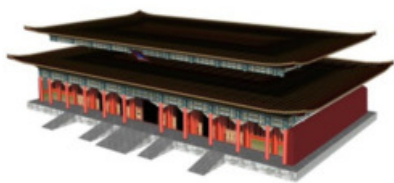

(j)

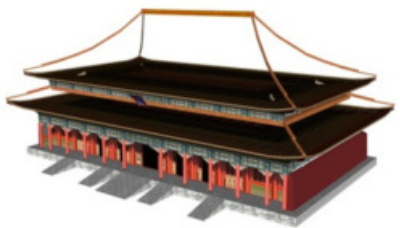

(e)

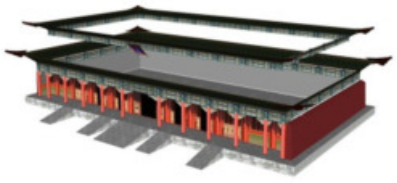

(h)

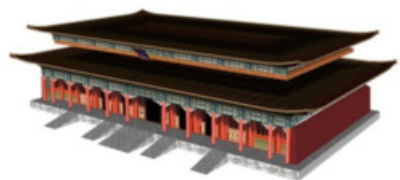

(k)

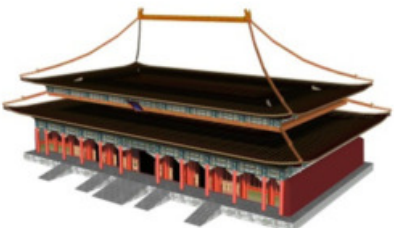

(f)

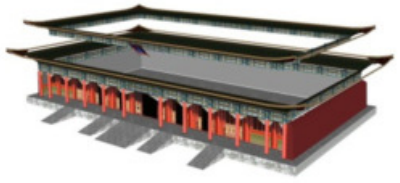

(i)

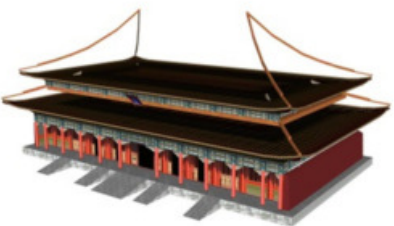

(l)

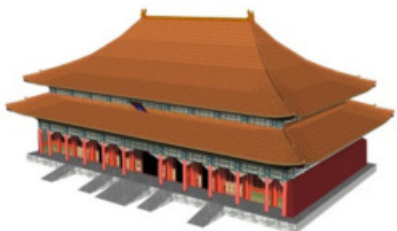

Figure 10. The bottom-up model process of Tai-he Palace. (a) Bottom ground; (b) add walls; (c) add doors, windows and pillars; (d) add dou-gongs (brackets); (e) add wing corners; (f) add main eaves; (g) add ceilings; (h) add horizontal ridges; (i) add vertical ridges; (j) add main ridge; (k) add chi'h-weis and tsun-shous; (1) last slope surfaces. Certain components, such as doors, windows and dou-gongs, are replaced by texture pictures for simplification.

(a)

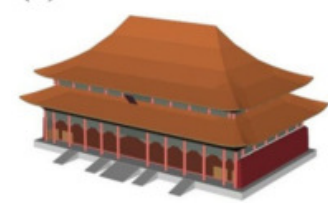

(f)

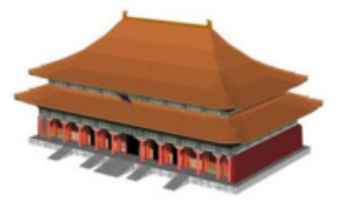

(b)

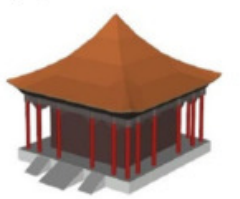

(g)

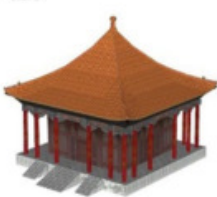

(c)

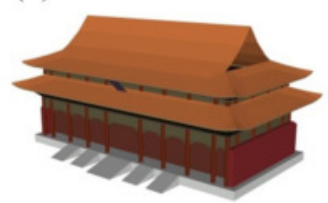

(h)

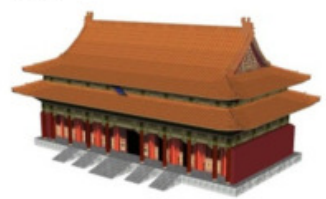

(d)

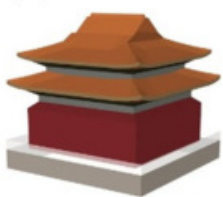

(i)

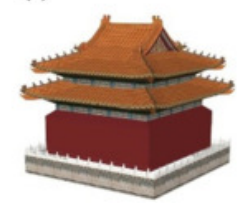

(e)

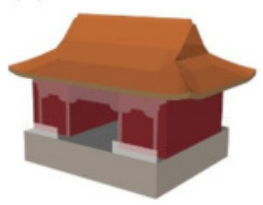

(j)

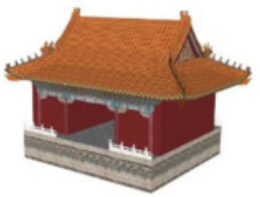

Figure 11. Five palace models displayed in LOD2 $(\mathbf{a}-\mathbf{e})$ and LOD3 $(\mathbf{f}-\mathbf{j})$. (Certain textures in LOD3 are highlighted in color; readers are referred to the electronic version of this paper).

\section{Conclusions and Perspectives}

In this study, we utilized a semantic modeling approach for ancient Chinese-style architectural roof styles by extracting the exterior roof components into two functional categories: structural and decorative. Semantic modeling may be more understandable and controllable for the unified description of the components. Relative topological rules were used to control the combination of the above-mentioned components and to validate the correctness of the model. Several transformative forms were listed to enrich the diversity of the building group. An application model termed ACRoofADE that extended CityGML was developed to express and ensure the consistency of the geometrical, semantic and topological relationships when rebuilding the roof models. To improve the display efficiency and ensure visual fidelity, three detail levels (LOD1, LOD2 and LOD3) were used according to the former semantic decompositions. 
The proposed method was tested on the principal buildings of the Palace Museum, which demonstrated the feasibility of the model. One advantage of this study is that it adopted a two-level semantic decomposition and topological reconstruction of complex 3D building models to allow the operator to focus on the structure design rather than cumbersome geometric drawings. In addition, the introduction of CityGML makes the previous thought feasible in practice, and the LOD concept further ensures accurate model representation.

After the primary exploration of 3D modeling for ancient Chinese-style architectural roofs, we envision several possible directions for future studies. The research scope could be broadened to the entire building structure, including the areas below the roof, to develop a complete research system. Moreover, interrelations, such as the degree of similarity between ancient Chinese-style architecture styles, could be analyzed to increase the efficiency of digitizing architectural heritages or guiding antique constructions.

Acknowledgments: We would like to acknowledge the editor and anonymous reviewers for their constructive comments to this article. This work was funded by the National Natural Science Foundation of China (No. 41471325), the Special Fund for Scientific Research of Surveying and Mapping in the Public Welfare (No. 201512032) and the Open Fund of the Key Laboratory of Urban Land Resources Monitoring and Simulation, Ministry of Land and Resources (No. KF-2015-0-054).

Author Contributions: This research was mainly performed and prepared by Lin Li and Lei Tang, who also contributed their ideas, and both conceived of and designed the study. Haihong Zhu and Hang Zhang contributed to analyzing the experimental results. Fan Yang and Wenmin Qin helped to review and edit the manuscript. All authors contributed to improving the paper.

Conflicts of Interest: The authors declare no conflict of interest.

\section{References}

1. Vecco, M. A definition of cultural heritage: From the tangible to the intangible. J. Cult. Herit. 2010, 11, 321-324.

2. Alves, S. Affordances of Historic Urban Landscapes: An Ecological Understanding of Human Interaction with the Past. Eur. Spat. Res. Policy 2014, 21, 13-31.

3. Yao, Y.; Han, R. Challenging, but not Trouble-Making: cultural elites in China's urban heritage preservation. J. Contemp. China 2016, 25, 292-306.

4. Tan, S.Y.; Olanrewaju, A.; Lee, L.T. Maintenance of Heritage Building: A Case Study from Ipoh, Malaysia. MATEC Web Conf. 2016, 47, 04003.

5. Yu Park, H. Shared national memory as intangible heritage: Re-imagining two Koreas as one nation. Ann. Tour. Res. 2011, 38, 520-539.

6. Yin, W.; Yamamoto, H. Standing tree assessment for the maintenance of historic wooden buildings: A case study of a World Heritage Site in China. iForest Biogeosci. For. 2013, 6, 169.

7. Catsadorakis, G. The conservation of natural and cultural heritage in Europe and the Mediterranean: A Gordian knot? Int. J. Herit. Stud. 2007, 13, 308-320.

8. Wong, C.U.I. The Preservation of Macau's Intangible Colonial Heritage: The Case of Patúa. Tour. Cult. Commun. 2014, 14, 91-102.

9. Ahmad, Y. The scope and definitions of heritage: From tangible to intangible. Int. J. Herit. Stud. 2006, 12, 292-300.

10. Liu, Y.; Xu, C.; Pan, Z.; Pan, Y. Semantic modeling for ancient architecture of digital heritage. Comput. Graph. 2006, 30, 800-814.

11. Li, D.; Yang, J.; Zhu, Y. Application of computer technic in the reconstruct of Chinese ancient buildings. Proc. SPIE 2003, 249-252, doi:10.1117/12.473119.

12. Fang, D.P.; Iwasaki, S.; Yu, M.H.; Shen, Q.P.; Miyamoto, Y.; Hikosaka, H. Ancient Chinese Timber Architecture. I: Experimental Study. J. Struct. Eng. 2001, 127, 1348-1357.

13. Tarsha-Kurdi, F.; Landes, T.; Grussenmeyer, P.; Koehl, M. Model-driven and data-driven approaches using LIDAR data: Analysis and comparison. Int. Arch. Photogramm. Remote Sens. Spat. Inf. Sci. 2007, 36, 87-92.

14. Brenner, C. Building reconstruction from images and laser scanning. Int. J. Appl. Earth Obs. Geoinform. 2005, 6, 187-198. 
15. Leeuwen, M.V.; Coops, N.C.; Wulder, M.A. Canopy surface reconstruction from a LiDAR point cloud using Hough transform. Remote Sens. Lett. 2010, 1, 125-132.

16. Sampath, A.; Shan, J. Segmentation and Reconstruction of Polyhedral Building Roofs From Aerial Lidar Point Clouds. IEEE Trans. Geosci. Remote Sens. 2010, 48, 1554-1567.

17. Yan, J.; Shan, J.; Jiang, W. A global optimization approach to roof segmentation from airborne lidar point clouds. ISPRS J. Photogramm. Remote Sens. 2014, 94, 183-193.

18. Xu, B.; Jiang, W.; Shan, J.; Zhang, J.; Li, L. Investigation on the Weighted RANSAC Approaches for Building Roof Plane Segmentation from LiDAR Point Clouds. Remote Sens. 2016, 8, 5.

19. Li, Y.; Ma, H.; Wu, J. Planar segmentation and topological reconstruction for urban buildings with lidar point clouds. In Proceedings of the International Symposium on Lidar and Radar Mapping 2011: Technologies and Applications, Nanjing, China, 26 May 2011

20. Wang, H.; Zhang, W.; Chen, Y.; Chen, M.; Yan, K. Semantic Decomposition and Reconstruction of Compound Buildings with Symmetric Roofs from LiDAR Data and Aerial Imagery. Remote Sens. 2015, 7, 13945-13974.

21. Sohn, G.; Dowman, I. Data fusion of high-resolution satellite imagery and LiDAR data for automatic building extraction. ISPRS J. Photogramm. Remote Sens. 2007, 62, 43-63.

22. Kim, C.; Habib, A. Object-Based Integration of Photogrammetric and LiDAR Data for Automated Generation of Complex Polyhedral Building Models. Sensors 2009, 9, 5679-5701.

23. Cheng, L.; Gong, J.; Li, M.; Liu, Y. 3D Building Model Reconstruction from Multi-view Aerial Imagery and Lidar Data. Acta Geod. Cartogr. Sin. 2009, 77, 125-139.

24. Awrangjeb, M.; Zhang, C.; Fraser, C.S. Automatic extraction of building roofs using LIDAR data and multispectral imagery. ISPRS J. Photogramm. Remote Sens. 2013, 83, 1-18.

25. Yang, L.; Sheng, Y.; Wang, B. 3D reconstruction of building facade with fused data of terrestrial LiDAR data and optical image. Optik Int. J. Light Electron Opt. 2016, 127, 2165-2168.

26. Buchele, S.F.; Crawford, R.H. Three-dimensional halfspace constructive solid geometry tree construction from implicit boundary representations. Comput. Aided Des. 2004, 36, 1063-1073.

27. Theis, C.; Buchegger, K.H.; Brugger, M.; Forkel-Wirth, D.; Roesler, S.; Vincke, H. Interactive three-dimensional visualization and creation of geometries for Monte Carlo calculations. Nucl. Instrum. Methods Phys. Res. 2006, $562,827-829$.

28. Wang, S.; Tseng, Y.H. Least-squares model-image fitting of floating models for building extraction from images. J. Chin. Inst. Eng. 2009, 32, 667-677.

29. Xiao, J.; Furukawa, Y. Reconstructing the world's museums. Int. J. Comput. Vis. 2014, 110, 243-258.

30. Luca, L.D.; Busayarat, C.; Stefani, C.; Véron, P.; Florenzano, M. A semantic-based platform for the digital analysis of architectural heritage. Comput. Graph. 2011, 35, 227-241.

31. Gröger, G.; Plümer, L. How to achieve consistency for 3D city models. GeoInformatica 2011, 15, 137-165.

32. Gröger, G.; Kolbe, T.; Nagel, C.; HÄfele, K. OGC City Geography Markup Language (CityGML) Encoding Standard; Open Geospatial Consortium Inc. (OGC): Wayland, MA, USA, 2012.

33. Gröger, G.; Plümer, L. Topology of surfaces modelling bridges and tunnels in 3D-GIS. Comput. Environ. Urban Syst. 2011, 35, 208-216.

34. Xie, X.; Zhu, Q.; Du, Z.; Xu, W.; Zhang, Y. A semantics-constrained profiling approach to complex 3D city models. Comput. Environ. Urban Syst. 2013, 41, 309-317.

35. Li, L.; Luo, F.; Zhu, H.; Ying, S.; Zhao, Z. A two-level topological model for 3D features in CityGML. Comput. Environ. Urban Syst. 2016, 59, 11-24.

36. Chan, C.S. Virtual reality modeling of traditional Chinese architecture. In Proceedings of the International Conference on Virtual Systems and Multimedia, Montreal, QC, Canada, 15-17 October 2003.

37. Zhang, X.C.; Zhao, H.T.; Sui, Y. Structural Behaviors of Chinese Historical Timber-Frame Buildings. Key Eng. Mater. 2012, 517, 705-709.

38. Jin, D.L. Discussion on Selection of Wood Structure of Ancient Buildings in China. J. Anhui Agric. Sci. 2012, $11,93$.

39. Teoh, S.T. Generalized descriptions for the procedural modeling of ancient East Asian buildings. In Proceedings of the Computational Aesthetics 2009: Eurographics Workshop on Computational Aesthetics, Victoria, BC, Canada, 28-30 May 2009; pp. 17-24.

40. Goldberg, M.Y. Greek Temples and Chinese Roofs. Am. J. Archaeol. 1983, 87, 305-310. 
41. Villi, G.; Pasut, W.; Carli, M.D. CFD modelling and thermal performance analysis of a wooden ventilated roof structure. Build. Simul. 2009, 2, 215-228.

42. Gou, A.; Wang, J. The development of roof color in ancient China. Color Res. Appl. 2010, 35, 246-266.

43. Liu, Y.; Xu, C.; Zhang, Q.; Pan, Y. The Smart Architect: Scalable Ontology-Based Modeling of Ancient Chinese Architectures. IEEE Intell. Syst. 2008, 23, 49-56.

44. Kolbe, T.H. Representing and exchanging 3D city models with CityGML. In 3D Geo-Information Sciences; Springer: Berlin/Heidelberg, Germany, 2009; pp. 15-31.

45. Li, L.; Wu, J.; Zhu, H.; Duan, X.; Luo, F. 3D modeling of the ownership structure of condominium units. Comput. Environ. Urban Syst. 2016, 59, 50-63.

46. Gröger, G.; Plümer, L. CityGML-Interoperable semantic 3D city models. ISPRS J. Photogramm. Remote Sens. 2012, 71, 12-33.

47. Liu, J.; Wu, Z.K. Rule-Based Generation of Ancient Chinese Architecture from the Song Dynasty. J. Comput. Cult. Herit. 2016, 9, 1-22.

48. Cheng, X.; Xia, Y.; Ma, Y.; Lei, Y. Three fabricated pigments (Han purple, indigo and emerald green) in ancient Chinese artifacts studied by Raman microscopy, energy-dispersive $\mathrm{X}$-ray spectrometry and polarized light microscopy. J. Raman Spectrosc. 2007, 38, 1274-1279.

(C) 2017 by the authors. Licensee MDPI, Basel, Switzerland. This article is an open access article distributed under the terms and conditions of the Creative Commons Attribution (CC BY) license (http:/ / creativecommons.org/licenses/by/4.0/). 